\title{
Simultaneous negative PLIF and OH* chemiluminescence imaging of the gas exchange and flame jet from a narrow throat pre-chamber
}

\author{
Qinglong Tang ${ }^{1}$, Ramgopal Sampath ${ }^{1}$, Manuel Echeverri Marquez ${ }^{1}$, Ponnya Hlaing ${ }^{1}$, Priybrat Sharma ${ }^{1}$, Moez Ben \\ Houidi $^{1}$, Emre Cenker ${ }^{2}$, Junseok Chang ${ }^{2}$, Gaetano Magnotti ${ }^{1}$, Bengt Johansson ${ }^{1}$ \\ ${ }^{1}$ King Abdullah University of Science and Technology, Clean Combustion Research Center, Thuwal, 23900, Saudi Arabia \\ ${ }^{2}$ Fuel Technology Division, R\&DC, Saudi Aramco, Dhahran 31311, Saudi Arabia
}

\begin{abstract}
Pre-chamber combustion (PCC) is a promising engine combustion concept capable of extending the lean limit at part load. The engine experiments in the literature showed that the PCC could achieve higher engine thermal efficiency and much lower $\mathrm{NO}_{x}$ emission than the spark-ignition engine. Improved understanding of the detailed flow and combustion physics of PCC is important for optimizing the PCC combustion. In this study, we investigated the gas exchange and flame jet from a narrow throat pre-chamber (PC) by only fueling the PC with methane in an optical engine. Simultaneous negative acetone planar laser-induced fluorescence (PLIF) imaging and $\mathrm{OH}^{*}$ chemiluminescence imaging were applied to visualize the $\mathrm{PC}$ jet and flame jet from the PC, respectively. Results indicate a delay of the PC gas exchange relative to the built-up of the pressure difference $(\Delta P)$ between PC and the main chamber (MC). This should be due to the gas inertia inside the PC and the resistance of the PC nozzle. The PC jet can be either continuous or intermittent depending on the $\Delta P$ and pressure fluctuation amplitude. Distinct PC jet with low speed is witnessed after $15^{\circ} \mathrm{CA}$ ATDC, which could account for the postcombustion of the PCC engine in the literature. The probability distribution analysis of the PLIF and $\mathrm{OH}^{*}$ images presents a much longer penetration length of the PC jet than that of the flame jet. This means that the flame jet resides in an atmosphere of the unburned gas mixture from the PC when it appears in the MC. The flame jet and PC jet show longer penetration length and become more stable with the enriching of the prechamber charge from lean to stoichiometric. However, the overall PC jet characteristics regarding the penetration length and probability distribution become less sensitive to the PC global excess air ratio $(\lambda)$ when the PC charge is close to stoichiometry.
\end{abstract}

\section{Introduction}

In the past decades, there has been an increasing demand for spark ignition (SI) engine efficiency improvement. The ideal Otto cycle indicates that higher compression ratio and specific heat ratio can boost engine efficiency. The practical SI engine compression ratio is restrained by the engine knock. So the lean combustion with higher specific heat ratio has long been regarded as a promising concept to achieve a higher engine efficiency. The pumping losses can be reduced in lean combustion through throttle-less operation. Besides, the lower combustion temperature during lean combustion lowers the $\mathrm{NO}_{x}$ emission and reduces the heat transfer loss, which further assists the efficiency improvement. However, for a fully premixed mixture, the narrow flammability limits of most fuels lead to unstable combustion, Page 1 of 13 which gives rise to increased UHC and CO emissions. For example, the gasoline SI engine will have severe cycle variation when the global excess air ratio $(\lambda)$ is higher than 1.4. To extend the lean limit while maintaining stable combustion becomes the key for the next generation of the lean-burn SI engine.

The pre-chamber combustion (PCC) is one feasible and low-cost solution to the lean burn challenges. The main idea is to use the chemically active turbulent jet from the prechamber to produce a distributed ignition source for the lean mixture in the cylinder. The prechamber (PC) with a small volume is equipped with a spark plug and a separated fuel supply. It is connected to the common engine cylinder (main chamber, MC) through several small orifices on the PC nozzle. A relatively fuel-rich charge generated in the PC is first ignited and then the hot combustion products, rich in radicals, are forced into the $\mathrm{MC}$ to ignite the lean premixed charge. Due to the limited passage area of the PC orifices, the pressure built-up $(\Delta P)$ between PC and MC can be tens of bars. It produces a very fast PC jet flow and intense turbulence into the MC. The PC works both as a hot-radicals injector and a turbulence generator, which enables a distributed multiple-point ignition and fast combustion in the MC [1,2]. In the last decade, extensive metal PCC engine experiments have been carried out. Attard et al. [3] showed that the PCC, implemented on a light-duty gasoline SI engine with a compression ratio of 10.4 , could extend the lean limit to $\lambda>2$ with stable combustion and ultra-low $\mathrm{NO}_{x}$ emission. In a comparative study, they achieved a $20 \%$ peak engine efficiency improvement for PCC compared to the SI mode [4]. The peak indicated net thermal efficiency in their 2012 work reached $42.8 \%$ [5]. The PCC also showed robust ignition quality [6] and high knock tolerance [7]. Ashish et al. [8, 9] investigated the PCC performance on a heavy-duty engine with a compression ratio of 12 and achieved a maximum gross indicated efficiency of $47.6 \%$. They also studied the effect of PC volume and nozzle diameter on PCC. Their finding of the optimum PC volume fraction of about $2.4 \%$ of the clearance volume agreed with the recommendation of Gussak in 1979 [1].

Further PCC optimization and efficiency improvement rely on a detailed understanding of the in-cylinder process of the PC and MC. Some optical diagnostic efforts have been made on exploring the jet discharge and combustion physics of PCC in constant volume chambers (CVC) and rapid compression machines (RCM). However, the significantly different boundary conditions on these apparatus could not reproduce the operating conditions of the engine. For example, the research carried out recently on CVC only had limited pressure of 1 to 5 bar [10-12], much lower than the PCC engine 
conditions. The difference in the operating pressure may cause disparities in the ignition mechanism. The works on RCM did not consider the intake and expansion process of the piston engine [13-15] that could substantially affect the residual gas scavenging and fuel/air charge distribution inside the PC, gas exchange between PC and MC, as well as emission formations from the PC.

Some studies on optical engines provided insights into the general combustion characteristics of the PCC. Murase et al. [16] proved the potential of the PC in controlling the start of HCCI combustion using high-speed natural flame luminosity (NFL) imaging. Using the same high-speed imaging technique, Kawabata et al. [17] asserted that the ignition and combustion of lean mixture in the MC can be promoted by increasing the number of the PC nozzle orifices. Toulson [18] and Attard [19] compared the combustion process of PCC and SI under the same optical engine and found that the PCC ignition presents much faster and more stable combustion at $\lambda=1.8$ compared to the SI mode at $\lambda=1.4$. Bunce et al. [20] applied high-speed $\mathrm{OH}^{*}$ and $\mathrm{CH}^{*}$ chemiluminescence imaging to evaluate the turbulent jet characteristics of a PCC engine. By comparing simultaneously acquired flame jet image and $\mathrm{PC} / \mathrm{MC}$ pressure, they found that the first visible flame jets appeared around the peak of the PC pressure for different PC nozzle orifices diameter designs. The first PLIF imaging of early flame development during PCC was implemented by Wellander et al. [21]. Only the MC was seeded with acetone tracer to visualize the flame jet region shown by the negative or dark area of images. The negative PLIF images showed intense interaction between the flame jet and the piston top.

The gas exchange between PC and MC before spark timing adds great complexity to the PCC ignition and the gas exchange after the MC combustion is also important for the emission formation of the PC. In Bunce's work mentioned above [20], the authors speculated that there must be a mass transfer from the PC to the MC between the pressure rise in the $\mathrm{PC}$ and the appearance of the visible flame jet. Mastorakos et al. [22] also inferred that the flame jet emerging from the PC should be surrounded by an atmosphere of unburned PC mixture. In a recent metal PCC engine experiment, Hlaing et al. [23] reported a "postcombustion" phenomenon that could be recognized on the heat release curve after the main combustion when running the engine with $\lambda=1.3$. This "post-combustion" was believed to be related to the gas exchange from PC after the MC combustion. However, to date, no detailed optical diagnostic experiment on the PC gas exchange has been done under practical engine conditions.

In the present study, a detailed picture of the gas exchange from the PC during and after the PC combustion was explored in a heavy-duty optical engine. To isolate the PC gas ejection phenomena, only the PC was fueled with natural gas. The focus is to evaluate PC performance without the MC combustion. Simultaneous negative acetone PLIF and line-of-sight $\mathrm{OH}^{*}$ chemiluminescence imaging were applied to visualize the PC jet and flame jet from the PC, respectively. The objectives are to (1) explore the spatial relationship between the PC jet and flame jet, (2) understand the gas exchange characteristics during and after PC combustion and find the reason for the "post-combustion" mentioned in the literature, (3) investigate the effect of PC charge enriching on the flame jet and $\mathrm{PC}$ jet penetration and stability.

\section{Experimental setups}

The experiment was carried out on a four-stroke, heavy-duty optical engine equipped with a PC assembly. One of the six cylinders was modified for optical study while the others were deactivated. The optical engine was equipped with a Bowditch extended piston with a Page 2 of 13 flat optical piston crown, as shown in Figure 1. The diameter of the optical piston is $130 \mathrm{~mm}$. Self-lubricating PTFE piston rings were used for combustion chamber sealing. Three optical windows were set on the side to provide access for laser and camera imaging. One UVmirror was set below the extended piston making the combustion chamber visible from the bottom view. The main optical engine specifications are listed in Table 1.

Table 1. Optical engine specifications

\begin{tabular}{|c|c|c|}
\hline Stroke & \multicolumn{2}{|c|}{$158 \mathrm{~mm}$} \\
\hline Bore & \multicolumn{2}{|c|}{$131 \mathrm{~mm}$} \\
\hline Displacement & \multicolumn{2}{|l|}{$2.1 \mathrm{~L}$} \\
\hline Compression Ratio & \multicolumn{2}{|l|}{9.5} \\
\hline Connecting Rod Length & \multicolumn{2}{|c|}{$255 \mathrm{~mm}$} \\
\hline Piston Shape & \multicolumn{2}{|l|}{ Flat } \\
\hline \multirow{2}{*}{ Intake Valve Timing } & Open & -330 CAD ATDC \\
\hline & Close & -170 CAD ATDC \\
\hline \multirow{2}{*}{ Exhaust Valve Timing } & Open & 180 CAD ATDC \\
\hline & Close & -340 CAD ATDC \\
\hline
\end{tabular}

Figure 2 shows the structure of the prechamber assembly and some key dimensions of the prechamber body. The PC body is fixed on an adaptor on which the spark plug and gas line are set. The prechamber assembly was designed to replace the original diesel injector of the optical engine without further modification to the cylinder head, as described in our previous works [23, 24]. Hence, it features a narrow throat with an inner diameter of $3.3 \mathrm{~mm}$ and a length of $25 \mathrm{~mm}$. The prechamber volume $\left(5.07 \mathrm{~cm}^{3}\right)$ and nozzle area-to-PC volume $(0.042$ $\mathrm{cm}^{-1}$ ) were determined based on the recommendation of Gussak [1]. Two rows of nozzle orifices, six orifices per row, are set on the PC due to the limited area of the nozzle tip. The nozzle orifices are evenly spaced along the radial direction. The diameter of the nozzle orifices is $1.5 \mathrm{~mm}$ and the included angle for both rows is $134^{\circ}$, as shown in Figure 2. The methane supply to the PC is controlled by a gas block injector and the fuel amount is measured by a mass flow meter. The methane injection pressure and timing are 7 bar and $-360^{\circ} \mathrm{CA}$ ATDC, respectively.

Table 2. Engine operating conditions

\begin{tabular}{|l|l|}
\hline Engine speed & $1200 \mathrm{rpm}$ \\
\hline Intake gas & Air \\
\hline Spark timing & $-15^{\circ} \mathrm{CA}$ ATDC \\
\hline Intake pressure & $1.2 \mathrm{bar}$ \\
\hline Intake temperature & $30 \pm 1{ }^{\circ} \mathrm{C}$ \\
\hline Coolant temperature & $78 \pm 2{ }^{\circ} \mathrm{C}$ \\
\hline Oil temperature & $88 \pm 2{ }^{\circ} \mathrm{C}$ \\
\hline PC Fuel & Methane $(99.5 \%$ purity $)$ \\
\hline PC injection pressure & 7 bar \\
\hline PC injection timing & $-360^{\circ} \mathrm{CA}$ ATDC \\
\hline
\end{tabular}

The engine was connected to a dynamometer and motored at 1200 revolutions per minute $(\mathrm{rpm})$ during the experiment. The engine intake boosting and the pre-heating system kept the intake pressure and temperature at 1.2 bar and $30^{\circ} \mathrm{C}$, respectively. The air mass flow rate was recorded by a mass flow meter. Acetone of $12 \mathrm{mg} / \mathrm{cycle}$ was 
injected into the intake port with 4 bar pressure at $-360^{\circ} \mathrm{CA}$ ATDC to premix with air and serve as the tracer for the PLIF. The spark timing was fixed at $-15^{\circ} \mathrm{CA}$ ATDC. The engine was fired continuously for 100 cycles for each test case. Two piezoelectric pressure sensors (Kistler 7061C in the MC and AVL GH15DK in the PC) recorded the $\mathrm{MC}$ and PC pressure separately during the experiment. The main engine operating conditions are summarized in Table 2.
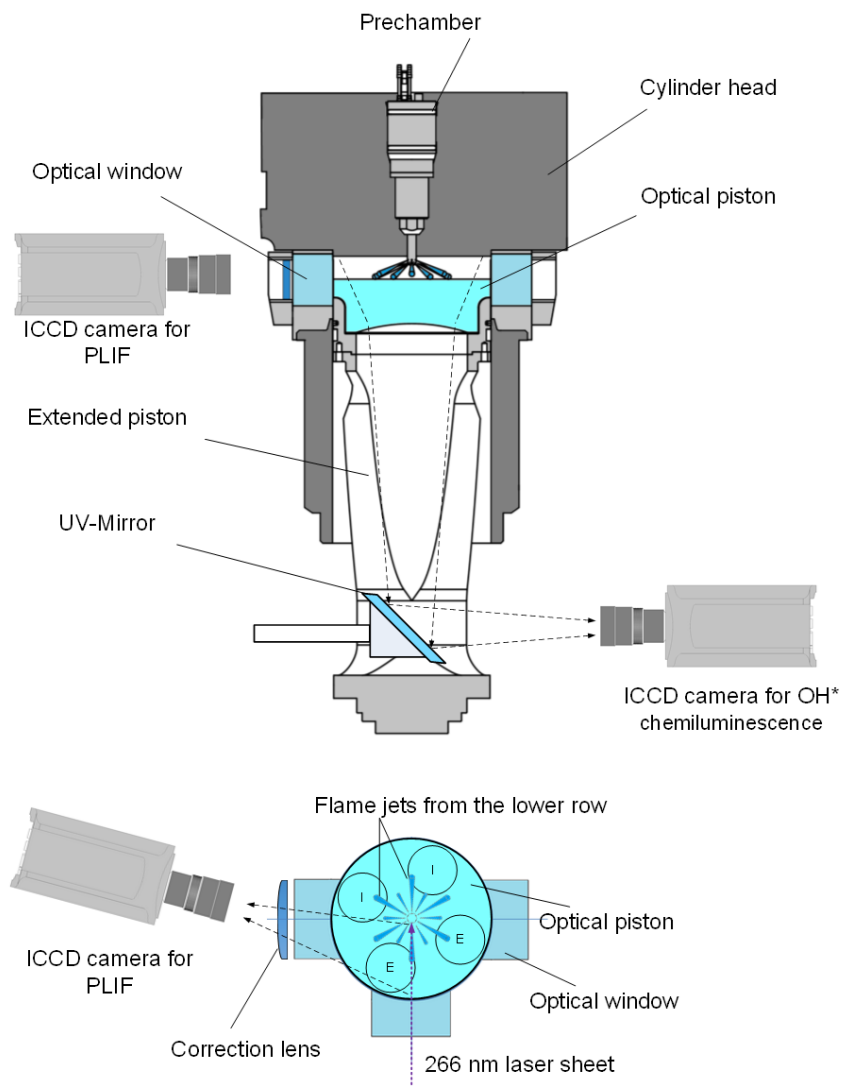

Figure 1. Schematic of the optical engine and simultaneous negative PLIF (side view) and $\mathrm{OH}^{*}$ chemiluminescence (bottom) imaging system.

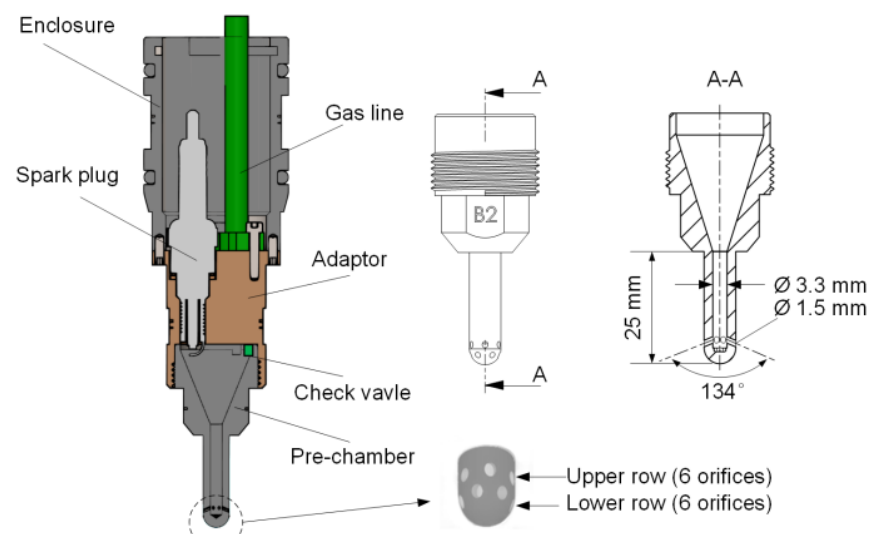

Figure 2. Pre-chamber assembly and key dimensions of the prechamber body (unit: $\mathrm{mm}$ ).

Page 3 of 13

\section{Negative fuel-tracer PLIF imaging from side view}

Figure 1 shows the schematic diagram of the simultaneous negative PLIF and $\mathrm{OH}^{*}$ chemiluminescence system. The fourth harmonic (266 $\mathrm{nm}, 27 \mathrm{~mJ} /$ pulse) of a $10 \mathrm{~Hz} \mathrm{Nd}$ :YAG laser (Q-smart 850, Quantel) was chosen for the acetone tracer excitation. The laser beam was formed into a vertical laser sheet less than $0.5 \mathrm{~mm}$ thick and $20 \mathrm{~mm}$ high by the laser sheet optics composed of three cylindrical lenses $\left(f_{1}=-\right.$ $20 \mathrm{~mm}, f_{2}=+100 \mathrm{~mm}$, and $f_{3}=+1000 \mathrm{~mm}$ ). The laser sheet was aligned along the centerline of one flame jet in the lower row of the orifices in the six o'clock direction.

An ICCD camera (PI-MAX3, Princeton Instruments), equipped with a Nikon $50 \mathrm{~mm}, \mathrm{f} / 1.2$ prime lens (within the visible light spectrum), was placed on the left side of the quartz liner and was tilted so that the whole targeted jet region could be visualized. One convex cylindrical lens was installed on the left window to correct the camera focusing issue caused by the side window. A tilt/shift lens mount adapter (Scheimpflug adapter) rotated the camera lens to a certain angle relative to the camera to correct the focus shift produced by the tilting of the ICCD camera. A high pass filter and a low pass filter were combined to capture the acetone PLIF signal in the range of 400-450 $\mathrm{nm}$. The gate width and gain level of the ICCD camera were $100 \mathrm{~ns}$ and $80 \%$, respectively.

\section{(a) Without distortion correction}

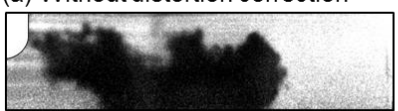

(b) With distortion correction

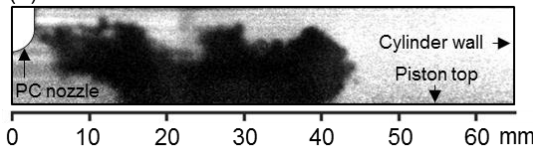

Figure 3. Comparison between the negative PLIF images without (a) and with (b) window distortion correction. The PC nozzle, cylinder wall, and piston top are marked out.

Acetone tracer was only seeded into the MC by intake port injection. There is no acetone seeding in the PC. When no gas or flame jet comes out from the PC, the field of view of the PLIF imaging in the MC would be filled uniformly with the acetone fluorescence signal. When the unseeded burned/unburned gas comes out from the PC or jet flame consumes the acetone in the $\mathrm{MC}$, it will show dark regions, as shown in Figure 3. In brief, the dark region or negative PLIF signal indicates $\mathrm{PC}$ jet issuing to the MC.

The PLIF images are processed as follows: Firstly, the averaged background image was subtracted from the PLIF image. Secondly, the PLIF image was normalized by the image acquired at the same crank angle without PC combustion. This step removes the potential effects of laser sheet non-uniformity. Thirdly, the distortion caused by the optical side window were corrected based on a grid-mapping technique using MATLAB image processing toolbox (piecewise linear dewarp algorithm). A similar correction procedure can be found in our previous works [25, 26] and the work of Miles et al. [27]. Figure 3 presents an example of the negative PLIF image without and with distortion correction. We can see distinct distortion caused by the optical window that would cause a big deviation to the actual jet penetration length. The location of the PC nozzle, cylinder wall, and piston top are marked out. 
The other ICCD camera (PI-MAX3, Princeton Instruments), equipped with a $45 \mathrm{~mm}, \mathrm{f} / 1.8 \mathrm{UV}$-lens (CERCO 2073, Sodern) and a bandpass filter with a transmission range of 300-330 nm, was used for line-ofsight $\mathrm{OH}^{*}$ chemiluminescence imaging from bottom view, as shown in Figure 1. The $\mathrm{OH}^{*}$ chemiluminescence signal is an indicator of the hot flame region. The gate width and the gain level of the ICCD camera were $140 \mu \mathrm{s}$ and $100 \%$, respectively. These two cameras were synchronized in time and the gate of the $\mathrm{OH}^{*}$ camera was $100 \mathrm{~ns}$ before the gate of the PLIF camera. Thus, the coupled images from PLIF and $\mathrm{OH}^{*}$ are assumed synchronized and considered to be at the same crank angle. Due to the low frequency of the laser, only one pair of PLIF and $\mathrm{OH}^{*}$ images could be acquired from one engine cycle. One hundred image pairs were recorded during the experiment for each crank angle of interest.

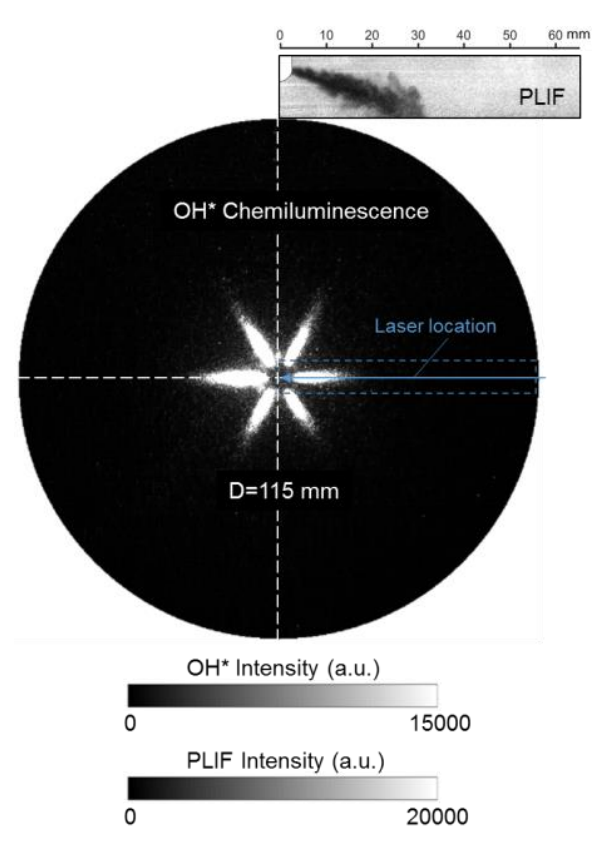

Figure 4. An example of the simultaneously acquired single-shot negative PLIF image (side view) and $\mathrm{OH}^{*}$ chemiluminescence image (bottom view) at $-8^{\circ} \mathrm{CA}$ ATDC for the PC2.4 case under the same proportional scale.

To choose the "typical" single-shot PLIF at specified crank angles, the 2-D correlation factors between each single-shot PLIF image and the average PLIF image were calculated. The single-shot PLIF image showing the highest correlation factor was selected as the typical single-shot image. Once the PLIF image was selected, the corresponding $\mathrm{OH}^{*}$ image was obtained. Figure 4 shows one pair of single-shot PLIF and $\mathrm{OH}^{*}$ images at $-8^{\circ} \mathrm{CA}$ ATDC for the PC 2.4 case, which is introduced in the next section. Note that the field of view of the $\mathrm{OH}^{*}$ imaging is $115 \mathrm{~mm}$ in diameter, smaller than the piston diameter of $130 \mathrm{~mm}$. The two grey-colorbar scales with the maximum signal intensity of 20000 and 1500 for PLIF and $\mathrm{OH}^{*}$ imaging, respectively. Only the 6 flame jets in the lower row of nozzle orifices are observed. The flame jet in the three o'clock direction is cut by the laser sheet. We can see that the penetration length of the PC jet is much longer than that of the flame jet under the same proportional scale.

Page 4 of 13

\section{Test matrix}

Table 3 shows the 3 test cases with an increasing prechamber methane fueling rate of $4.8,9.6$, and $14.2 \mathrm{mg}$ per cycle. The fueling of the latter two cases is doubled and tripled over the first case. No fuel was supplied into the MC so that the performance of the PC can be evaluated separately using negative PLIF imaging. The ratio of methane volume per cycle to the PC volume is $1.2,2.4$, and 3.6, respectively. These four cases are denoted as PC1.2, PC2.4, and PC3.6, respectively, for brevity.

Table 3. Test cases

\begin{tabular}{|c|c|c|c|}
\hline $\begin{array}{c}\text { PC fueling } \\
\text { rate } \\
\text { (mg/cycle) }\end{array}$ & $\begin{array}{c}\text { MC fueling rate } \\
\text { (mg/cycle) }\end{array}$ & $\begin{array}{c}\text { Ratio of methane } \\
\text { volume per cycle to PC } \\
\text { volume }\end{array}$ & $\begin{array}{c}\text { Estimated } \\
\text { PC } \lambda\end{array}$ \\
\hline 4.8 & 0 & $\mathbf{1 . 2}$ & 1.51 \\
\hline 9.6 & 0 & $\mathbf{2 . 4}$ & 1.15 \\
\hline 14.2 & 0 & $\mathbf{3 . 6}$ & 0.99 \\
\hline
\end{tabular}

To estimate the PC $\lambda$, a 1-D simulation model was set up in the GTPower software. The model map is shown in the Appendix. The PC and the $\mathrm{MC}$ are simulated using the $\mathrm{PC}$ and engine cylinder objects, respectively. The PC nozzles are simulated using the nozzle object. The instantaneous intake pressure is imposed as a boundary condition into the intake manifold. Since the experiments were performed without a back-pressure valve after the engine exhaust outlets, the pressure in the exhaust fold is imposed as the atmospheric pressure. The valve lift profiles of the intake and exhaust valves are measured from the experimental engine. The fuel addition to the $\mathrm{PC}$ is achieved by adding an injector object on top of the PC object. The start of injection and the duration of injection is taken from the experiments. The measured PC and MC pressure traces are compared against the simulated pressure traces. The discharge coefficients through the PC nozzles, both in the forward and reverse directions, are adjusted to calibrate the pressure traces.

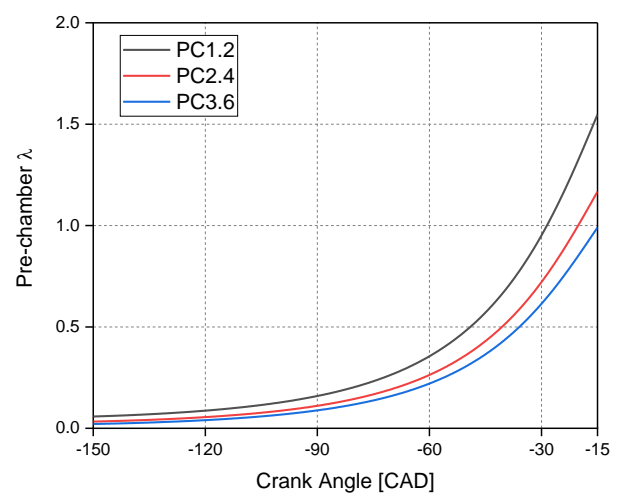

Figure 5. Pre-chamber (PC) $\lambda$ evolution estimated by a 1-D GT-Power model.

Figure 5 shows the estimated PC $\lambda$ evolution. The estimated PC $\lambda$ at the spark timing of $-15^{\circ} \mathrm{CA}$ ATDC for these three cases is $1.51,1.15$, and 0.99 , respectively. By studying these three cases, we can learn the in-cylinder characteristics of gas exchange and flame jet from the PC with PC charge enrichment from lean condition (1.51) to stoichiometric (0.99) condition. 


\section{Results and discussion}

The PC3.6 case is taken as an example to show the averaged PC and MC pressure in Figure 6. The PC pressure in the compression stroke before spark ignition is lower than the MC pressure due to the flow restriction imposed by the small nozzle orifices. The $\mathrm{MC}$ gas will enter into the PC during this stage. After spark ignition, the PC pressure exceeds the $\mathrm{MC}$ pressure quickly and reaches its peak around $-8.5^{\circ} \mathrm{CA}$ ATDC. Then the PC pressure drops below the MC pressure and shows some pressure fluctuation. After about $15^{\circ} \mathrm{CA}$ ATDC, the PC pressure is higher than the MC pressure due to the MC volume expansion at this stage of the cycle. In this work, we use the negative PLIF imaging to visualize the gas exchange from PC to MC.

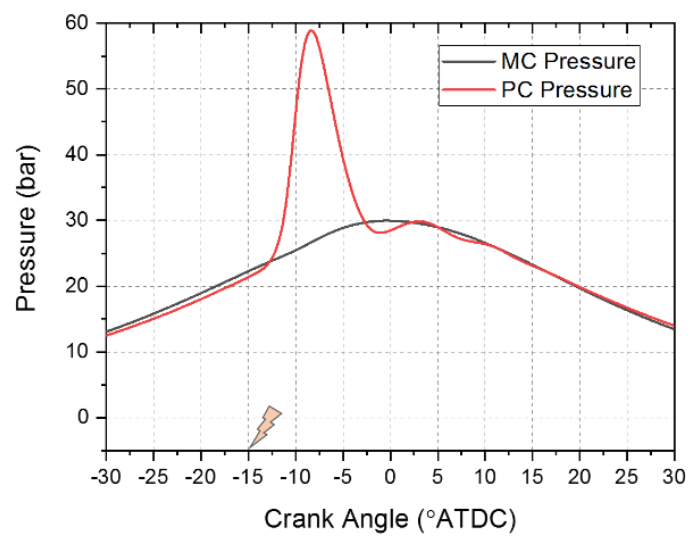

Figure 6. Pre-chamber $(\mathrm{PC})$ pressure and main chamber $(\mathrm{MC})$ pressure for the PC3.6 case.

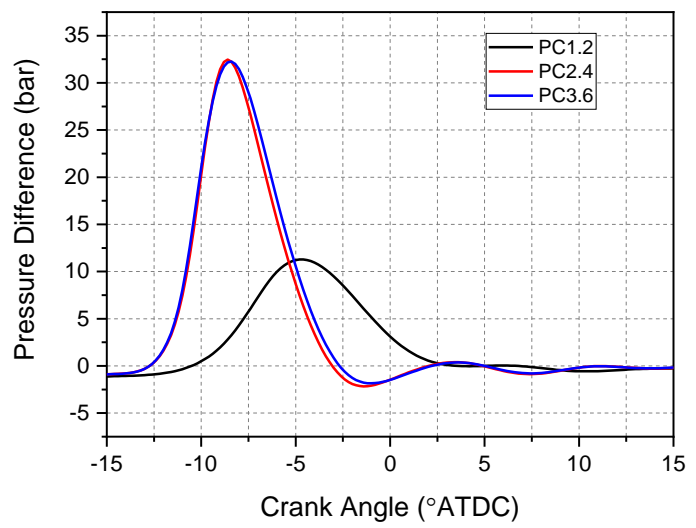

Figure 7. Pressure difference between pre-chamber (PC) and main chamber (MC).

Figure 7 presents the averaged pressure difference $(\Delta P)$ between PC and $\mathrm{MC}$ for all three cases. The ignition timing indicated by the timings of the $\Delta P$ rise, as well as the timing of peak $\Delta P$, are advanced while the peak pressure gets higher with the enriching of the prechamber. The PC3.6 case has similar ignition timing and peak pressure to the PC2.4 case. It only shows a slightly longer combustion duration for the PC3.6 case compared to the PC2.4. The above combustion characteristics agree with the estimated PC $\lambda$ listed in Table 3. Decreasing PC $\lambda$ from 1.51 to 0.99 , the ignition timing and the peak $\Delta P$ timing first advances and then remain similar.

\section{PC jet imaged by PLIF}

To show the detailed gas exchange process from the PC to MC, the single-shot PLIF image from a typical cycle and the averaged negative PLIF from 100 cycles at specified crank angles, as well as the averaged $\triangle P$ between $P C$ and $\mathrm{MC}$, are listed in three panels from right to left for each case in Figure 8, Figure 9 and Figure 10. The single-shot PLIF images can show more details of the turbulent PC jet structure and the interaction between the $\mathrm{PC}$ jet and the piston top wall. The averaged PLIF images remove the effect of cycle variation and give a general view of the PC jet distribution so that it can be directly linked to the average $\Delta P$ trace.

For the PC1.2 case in Figure 8, no PC jet shows up before $-7^{\circ} \mathrm{CA}$ even though the pressure has started to built-up in the PC. The PC jet appears at $-6^{\circ} \mathrm{CA}$ when the $\mathrm{PC}$ pressure approaches to its maximum. This delay between the pressure build-up and the first PC jet in $\mathrm{MC}$ is due to the gas inertia and resistance of the PC nozzle to the viscous gas inside the PC. The feature of the long throat design (see Figure 2) of the PC may prolong this delay. Then, the PC jet starts to impinge on the piston top after $-3^{\circ} \mathrm{CA}$. When the pressure difference approaches zero between $2^{\circ}$ and $4^{\circ} \mathrm{CA}$, the $\mathrm{PC}$ jet loses driving force, but it persists because of inertia. The PC jet reduces greatly from $4^{\circ}$ and $6^{\circ}$ $\mathrm{CA}$ and gets quite weak in between $8^{\circ}$ and $10^{\circ} \mathrm{CA}$. From $12^{\circ}$ to $30^{\circ}$ $\mathrm{CA}$, the PC jet becomes stronger again. This is because the MC pressure drops faster than PC during the cylinder volume expansion with the moving down of the piston. The remained burned/unburned mixture comes out from PC forming the PC jet. Overall, the PC jet always shows up for the PC1.2 case. This is mainly because the combustion intensity is low and only a small pressure fluctuation is produced after the PC combustion. This will be further discussed in the following two cases.

As shown in Figure 9, the PC2.4 case presents an earlier first PC jet image at $-9^{\circ} \mathrm{CA}$, close to the peak PC pressure, due to the earlier ignition timing and combustion phasing. The higher $\Delta P$ leads to a higher gas flow rate indicated by the much darker PLIF intensity in the jet region. The higher gas flow momentum results in stronger impingement between the $\mathrm{PC}$ jet and piston top at $-7^{\circ} \mathrm{CA}$. The vortex structure formed after wall impingement in the leading edge of the PC jet is more distinct from $-6^{\circ}$ to $-2^{\circ} \mathrm{CA}$. Different from the PC1.2 case, the pressure difference fluctuation after PC combustion is much stronger, showing evident negative value between $-3^{\circ}$ to $2^{\circ} \mathrm{CA}$ and $6^{\circ}$ to $10^{\circ} \mathrm{CA}$. 


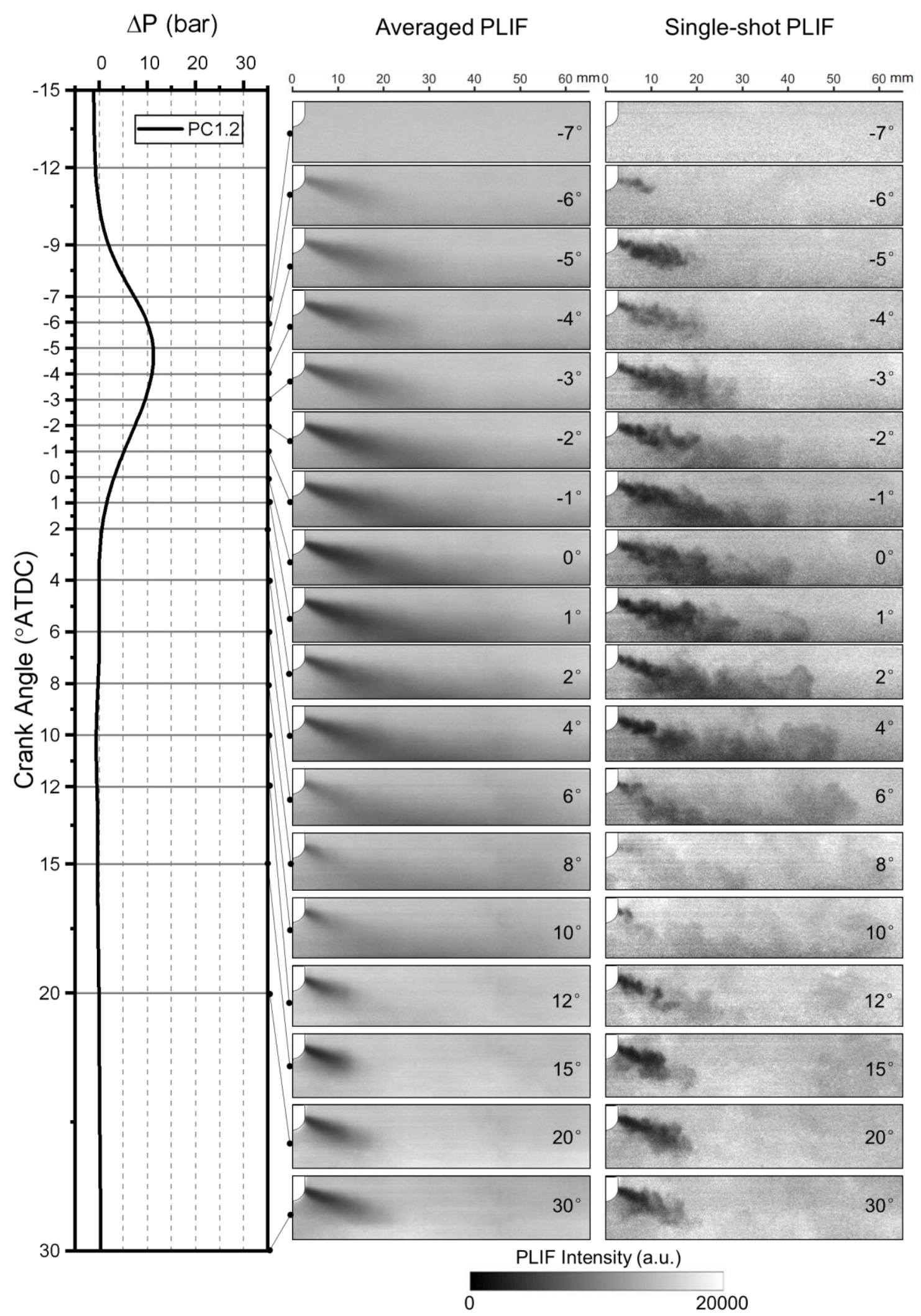

Figure 8. Averaged pressure difference ( $\triangle P$, left), averaged PLIF (middle) and single-shot (right) PLIF images showing the PC jet for the PC1.2 case. 


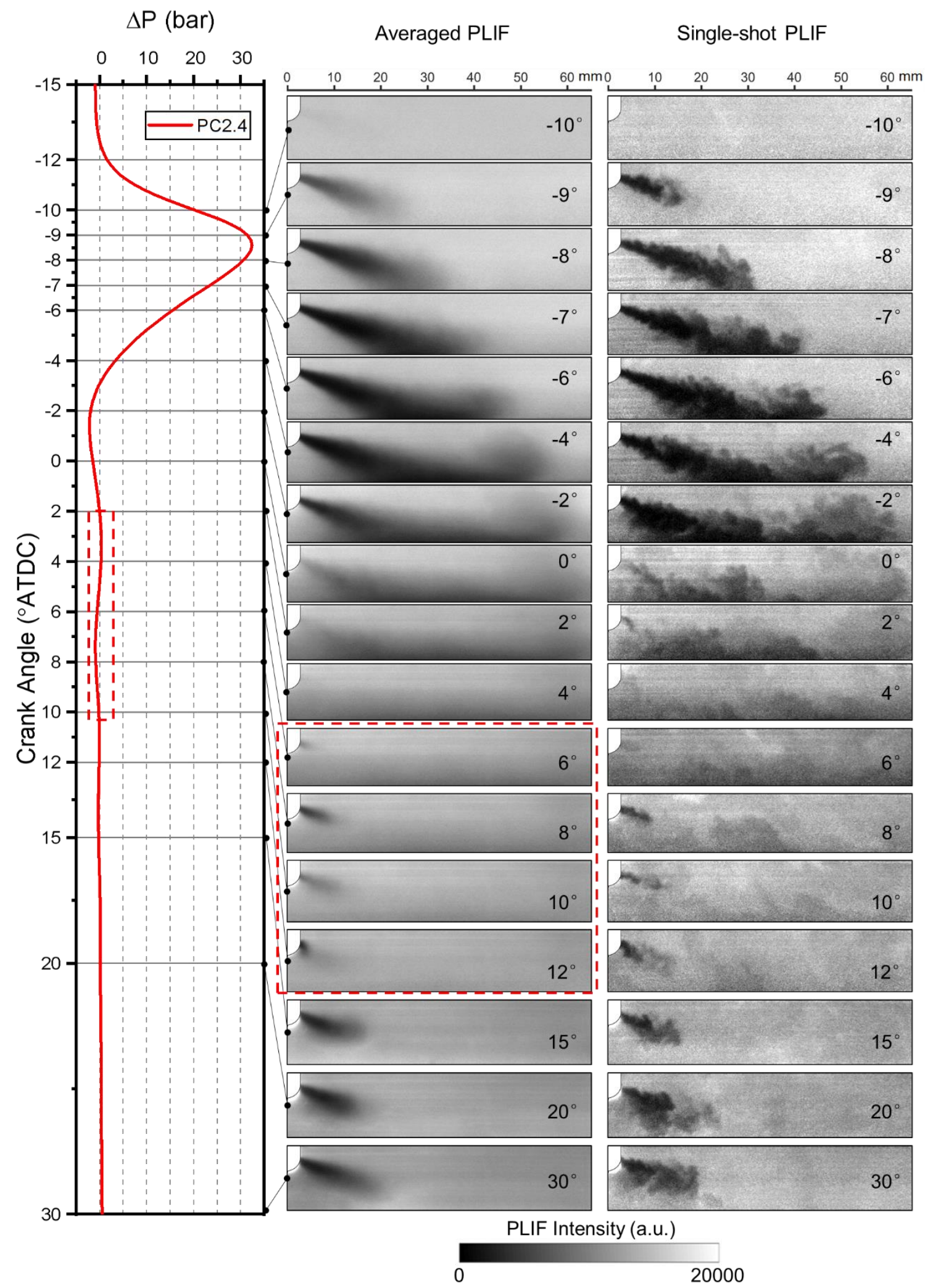

Figure 9. Averaged pressure difference ( $\triangle P$, left), averaged (middle) and single-shot (right) PLIF images showing the PC jet for the PC2.4 case. The second-stage gas exchange from the PC is shown with the two red dashed rectangles. The delay between the build-up of $\triangle P$ and the actual gas exchange is highlighted.

Page 7 of 13 


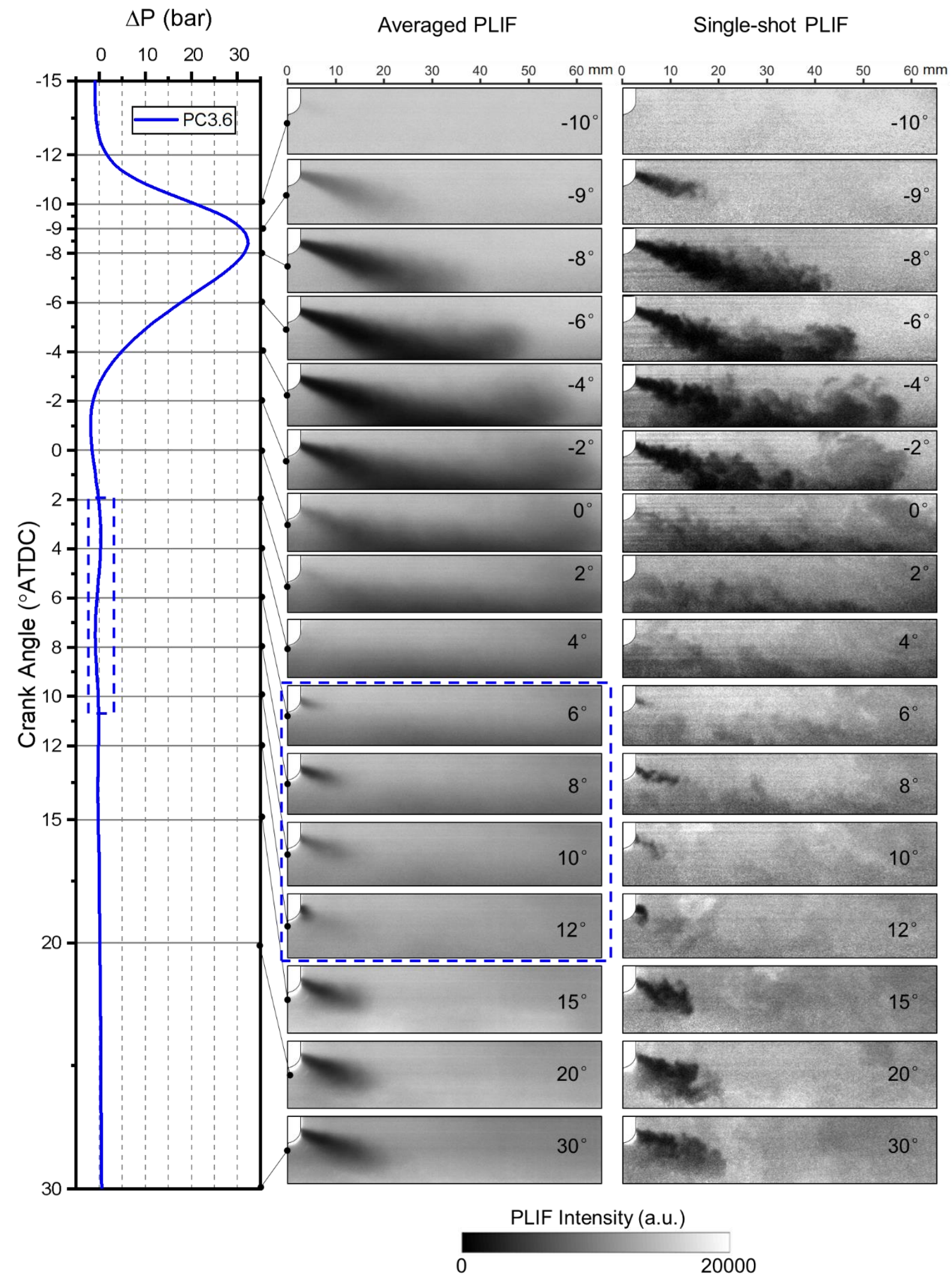

Figure 10. Averaged pressure difference ( $\triangle P$, left), averaged (middle) and single-shot (right) PLIF images showing the PC jet for the PC3.6 case. The second-stage gas exchange from the $\mathrm{PC}$ is shown with two blue dashed rectangles. The delay between the build-up of $\Delta P$ and the actual gas exchange is highlighted.

Page 8 of 13 
Due to this pressure fluctuation, the gas exchange from PC after combustion is not continuous anymore and it can be divided into three stages. The first stage is from $-9^{\circ}$ to $2^{\circ} \mathrm{CA}$ in which the $\mathrm{PC}$ jet is caused by the pressure difference during $\mathrm{PC}$ combustion. It is interesting to notice that the $\mathrm{PC}$ jet persists at $-2^{\circ}$ and $0^{\circ} \mathrm{CA}$ although the pressure difference is negative. On the contrary, there is no $\mathrm{PC}$ jet from $2^{\circ}$ and $4^{\circ} \mathrm{CA}$ with positive pressure difference. This phenomenon is due to the aforementioned "delay" between the pressure difference and the gas exchange caused by the inertia of the gas inside the PC and resistance of the PC. As shown by the red rectangle in Figure 9, the second-stage gas exchange between $6^{\circ}$ and $12^{\circ} \mathrm{CA}$, increasing first then decreasing again, is due to the positive pressure difference between $2^{\circ}$ and $5^{\circ} \mathrm{CA}$, and the negative pressure difference between $6^{\circ}$ and $10^{\circ} \mathrm{CA}$, respectively. The third-stage gas exchange rises from $12^{\circ}$ to $30^{\circ} \mathrm{CA}$ due to the positive $\Delta P$ due to the volume expansion caused by piston motion. The flow rate is higher compared to the PC1.2 case, showing lower PLIF intensity in the PC jet region.

Figure 10 shows that the overall gas exchange of the PC3.6 case is quite similar to that of the PC2.4 case, consistent with the similar $\Delta P$ trace. A same three-stage gas exchange caused by the pressure difference fluctuation is observed in this case, with a similar delay. The second-stage gas exchange is marked out by a blue dashed rectangle.

It's worth noting that all three cases mentioned above present a distinct PC jet with low speed after $15^{\circ} \mathrm{CA}$ ATDC. This gas exchange can explain why our previous metal PCC engine experiment with both PC and $\mathrm{MC}$ fueling showed a post-combustion process after the main heat release [23]. In that scenario, the unburned mixture inside the PC comes out into the MC after TDC and is burned out thereafter.

\section{Flame jet from the $\mathrm{PC}$ shown by $\mathrm{OH}^{*}$ chemiluminescence}

Figure 11 presents the flame jets indicated by the averaged $\mathrm{OH}^{*}$ chemiluminescence in three columns for all three cases. For the PC 1.2 case, only the six flame jets from the lower row of PC nozzle orifices are observed. The $\mathrm{OH}^{*}$ intensity is low with very short flame penetration length. The very weak flame jets persist late until $4^{\circ} \mathrm{CA}$, which corresponds to the last PLIF image at $4^{\circ} \mathrm{CA}$ in Figure 8 showing distinct PC jet from the PC. In comparison, the PC2.4 case shows much stronger $\mathrm{OH}^{*}$ signal intensity and longer flame jet penetration length. The very weak flame jets from the upper row of orifices with very short penetration length can be seen at $-9^{\circ}$ and $-8^{\circ} \mathrm{CA}$, which are in between the lower-row flame jets. The $\mathrm{OH}^{*}$ image at $-8^{\circ} \mathrm{CA}$ is enlarged in Figure 11 to give a better view. The flame jets from the upper row are much less pronounced compared to the lower row. The observed behavior is due to the PC nozzle orifice design. As shown in Figure 2, the upper row of orifices is arranged on the straight part of the throat. However, the lower row of orifices is on the curved surface of the PC throat tip. When the gas or flame flows downward inside the straight throat during PC combustion, the lower-row orifices have a larger momentum component and thus higher flow rate. This explanation will be further verified via PC inner nozzle area diagnostic or simulation efforts in the future. Although the current study did not measure the negative PLIF imaging of the upper-row orifices (the laser sheet is aligned to the lower row orifice), the $\mathrm{OH}^{*}$ images suggest that the gas exchange is much weaker than that of the lower-row orifices shown in Figure 8-10.

Page 9 of 13

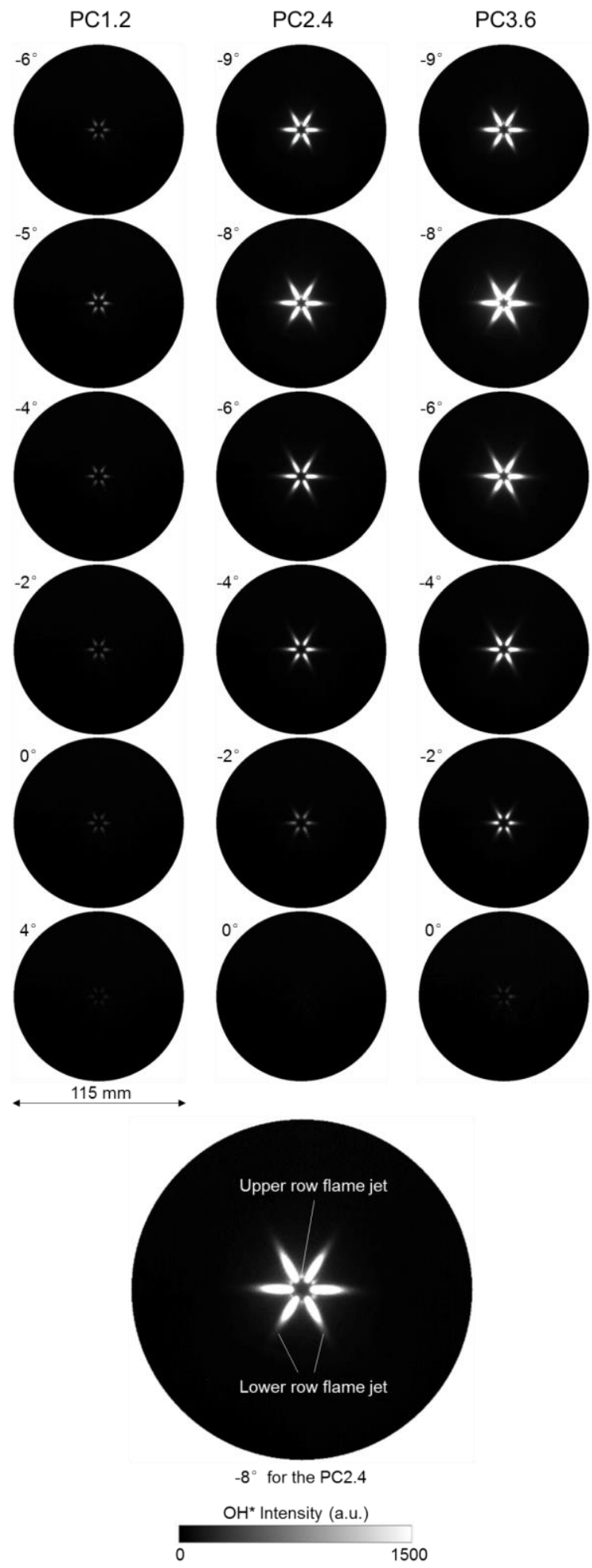

Figure 11. Averaged $\mathrm{OH}^{*}$ chemiluminescence images in the main chamber. The image at $-8^{\circ}$ for the PC 2.4 case is magnified by a factor of 2 to show more details of the flame jet from the nozzle orifices in the upper row and lower row. The gray colorbar scale is in Figure 4.

Unexpectedly, the $\mathrm{OH}^{*}$ chemiluminescence intensity of the PC3.6 case is apparently higher and flame jet penetration length longer than that of the PC2.4 case at the same crank angles although the PC peak pressure, combustion phasing and gas exchange between $\mathrm{PC}$ and $\mathrm{MC}$ 
of PC2.4 and PC3.6 are quite similar. Note that there is no flame jet observed after $4^{\circ} \mathrm{CA}$ for all three cases, hence images after $4^{\circ} \mathrm{CA}$ are not shown here. This means that only the PC jet during the PC combustion in Figure 8-10 (the first-stage gas exchange for PC2.4 and PC 3.6 case) is accompanied by flame jet. To further compare the flame jet and PC jet penetration length during this stage, a more detailed probability distribution analysis is carried out in the following section.

\section{Probability distribution of the PC jet and flame jet}

To quantify the horizontal penetration length of the PC jet and flame jet, image binarization was applied to all the single-shot PLIF and $\mathrm{OH}^{*}$ images using the threshold of about $10 \%$ of the maximum signal intensity. The number $n$ image of PLIF or $\mathrm{OH}^{*}$ is binarized to detect the PC jet or flame jet boundary. The value at pixel $(x, y)$ inside the PC jet or flame jet region, $i_{(x, y)}$, is assigned to 1 . The value of the pixels out of the PC jet or flame jet region is assigned to 0 . The probability distribution index $(P D I)$ at pixel $(x, y)$ is determined by combining all the 100 images from 100 separate cycles using the following equation.

$$
P D I_{(x, y)}=\left(\sum_{n=1}^{100} i_{(x, y)}\right) / 100
$$

The PDIs of the PLIF and $\mathrm{OH}^{*}$ images are used to show the possibility of the flame jets or PC jets occurrence. $P D I_{(x, y)}=0$ means that there is no $\mathrm{PC}$ jet or flame jet at pixel $(\mathrm{x}, \mathrm{y})$ in all the 100 images and $P D I_{(x, y)}=1$ means that there is always $\mathrm{PC}$ jet or flame at pixel $(\mathrm{x}, \mathrm{y})$ for all the 100 images. The PDI also serves as an indicator of the cycleto-cycle variation of the flame jets or PC jets at specified crank angles

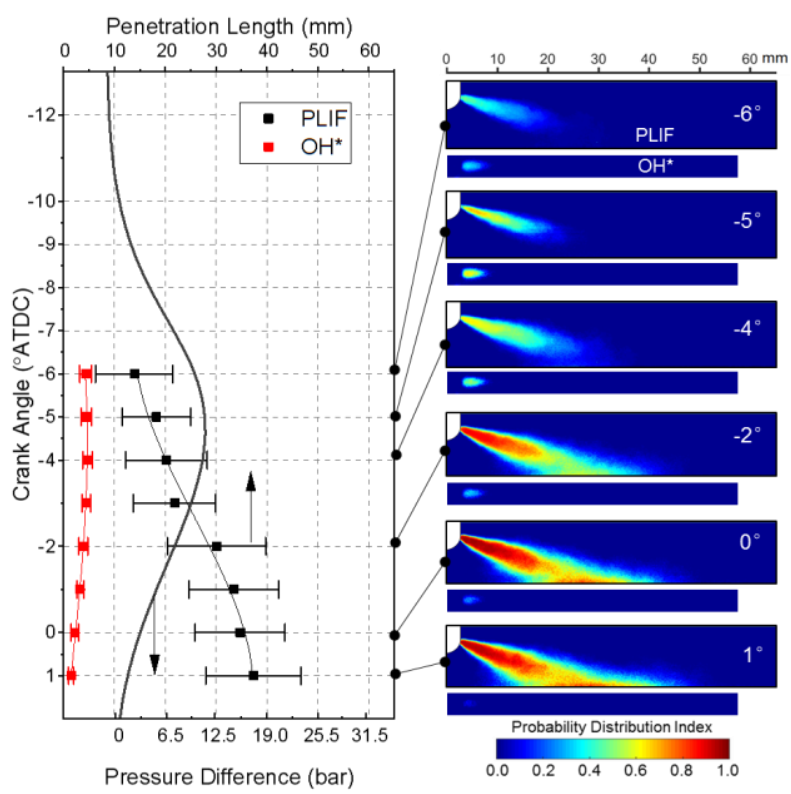

Figure 12. Horizontal penetration length of the negative PLIF and $\mathrm{OH}^{*}$ chemiluminescence and the probability distribution of the negative PLIF and $\mathrm{OH}^{* *}$ chemiluminescence for the PC1.2 case

The left panel of Figure 12 presents the horizontal penetration length of the PC jet and flame jet as well as the pressure difference for the PC1.2 case. The right panel shows the probability distribution of the corresponding PC jet and flame jet. We can see that the flame jet penetration length is much shorter than that of the $\mathrm{PC}$ jet penetration length. The maximum flame jet penetration length at $-5^{\circ} \mathrm{CA}$, which is Page 10 of 13 very close to the peak $\mathrm{PC}$ pressure, is about $4.5 \mathrm{~mm}$. The maximum $\mathrm{PC}$ jet penetration length at $1^{\circ} \mathrm{CA}$ is about $37 \mathrm{~mm}$. The overall $P D I$ of the PC jet and flame jet for the PC1.2 cases is relatively low, indicating higher cycle-to-cycle variation, especially the region close to the piston top.

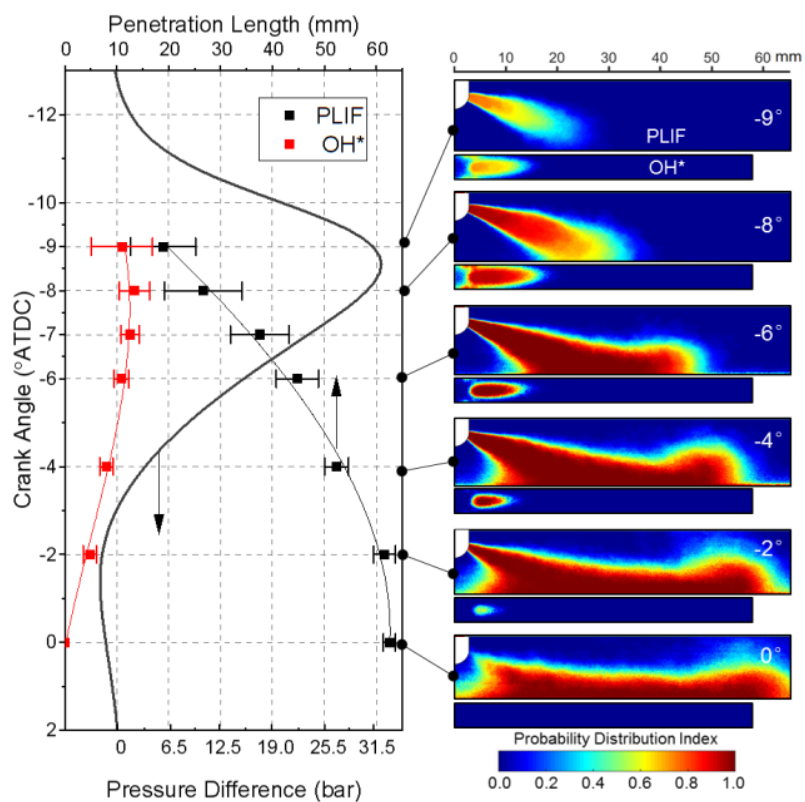

Figure 13. Horizontal penetration length of the negative PLIF and $\mathrm{OH}^{*}$ chemiluminescence and the probability distribution of the negative PLIF and $\mathrm{OH}^{*}$ chemiluminescence for the PC2.4 case.

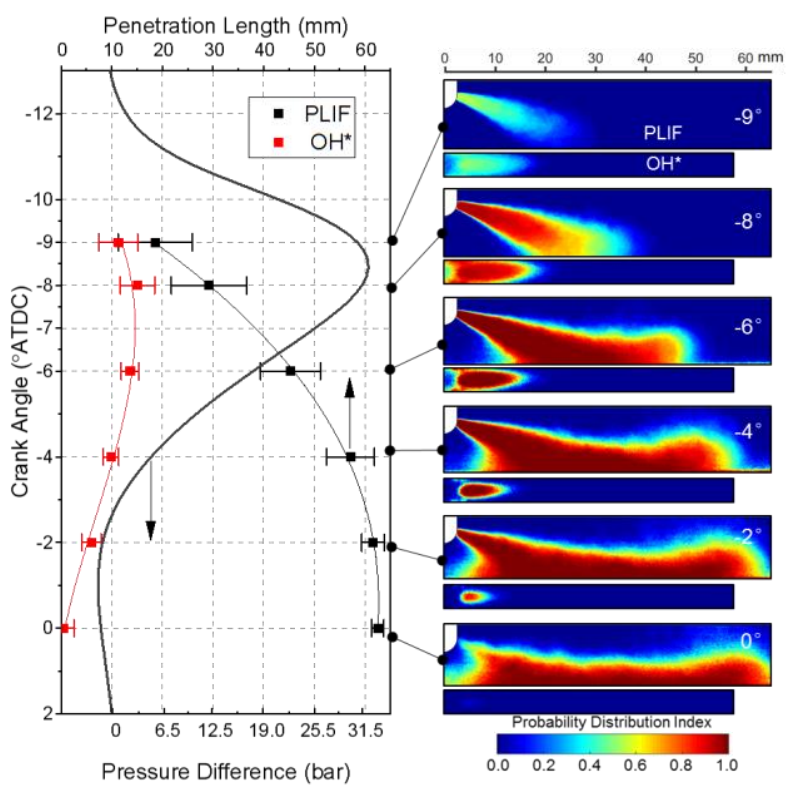

Figure 14. Horizontal penetration length of the negative PLIF and $\mathrm{OH}^{*}$ chemiluminescence and the probability distribution of the negative PLIF and $\mathrm{OH}^{*}$ chemiluminescence for the PC3.6 case.

In comparison to the PC1.2 case, the PC2.4 case in Figure 13 shows a much higher overall PDI in both the flame jet region and the PC jet region. This means the flame jet and $\mathrm{PC}$ jet is more stable with smaller cycle variation. The high $P D I$ of gas flow near the piston top indicates 
a strong interaction between the PC jet and the piston top. The head vortex of the PC jet formed after impinging on the piston top can be observed after $-6^{\circ} \mathrm{CA}$. The PC jet starts to impinge on the cylinder wall at $0^{\circ} \mathrm{CA}$. The maximum mean horizontal $\mathrm{PC}$ jet penetration speed at $-8^{\circ} \mathrm{CA}$ for the PC2.4 case is $56.1 \mathrm{~m} / \mathrm{s}$, which is much higher than the $31.3 \mathrm{~m} / \mathrm{s}$ for the $\mathrm{PC} 1.2$ case at $-5^{\circ} \mathrm{CA}$. The maximum flame jet penetration for the PC 2.4 case at $-8^{\circ} \mathrm{CA}$, close to the peak PC pressure, is about $13.4 \mathrm{~mm}$.

Figure 14 shows that the overall PC jet probability distribution of the PC3.6 case is quite similar to that of the PC2.4 case. The PC jet penetration length is also similar to each other. However, the overall flame jet penetration length of the PC3.6 is longer than that of the PC2.4 case. The maximum flame jet penetration length at $-8^{\circ} \mathrm{CA}$, close to the peak PC pressure, is about $15.1 \mathrm{~mm}$. Except for the crank angle of $-9^{\circ} \mathrm{CA}$, the PDI of the flame jet of the PC3.6 case is also higher than that of the PC2.4 case, indicating a more stable flame jet.

In summary, with the enrichment of the PC charge from lean to stoichiometric condition, the flame jet and PC jet show longer penetration length and become more stable. However, the PC jet characteristics regarding the penetration length and probability distribution become less sensitive to the $\mathrm{PC} \lambda$ when the PC charge is close to stoichiometry. Figure 12-14 also show that the flame jets are always attached to the nozzle, meaning that the flame propagating in the PC is not quenched when discharged to MC through the nozzle orifices. By comparing the spatial distribution of flame jet indicated by $\mathrm{OH}^{*}$ chemiluminescence and the PC jet indicated by the negative PLIF imaging, we can see that the flame jet resides in an atmosphere of the unburned gas mixture from the PC when it appears in the MC.

\section{Conclusions}

In this study, the gas exchange and flame jet from a narrow throat prechamber (PC) were investigated by fueling only the PC with methane in an optical engine. We applied simultaneous negative acetone PLIF imaging from the side view and $\mathrm{OH}^{*}$ chemiluminescence imaging from the bottom view to visualize the PC jet and flame jet, respectively. Three ratios of fuel volume per cycle to prechamber volume were studied: 1.2 (PC1.2 case), 2.4 (PC2.4 case), and 3.6 (PC3.6 case). The 1-D GT-Power model estimated that the PC charge was enriched from $\lambda=1.51$ and $\lambda=1.15$ to $\lambda=0.99$ with the increase of the PC fueling. Some conclusions and implications are obtained by analyzing the gas exchange, $\mathrm{PC}$ jet, and flame jet characteristics of these three cases.

(1) When the PC charge is enriched from lean $(\lambda=1.51)$ to stoichiometry $(\lambda=0.99)$, the pressure difference between PC and MC $(\triangle P)$ first increases and then reaches a plateau. Similarly, the ignition timing and timing of peak $\Delta P$ first advance and then reach a plateau. The overall combustion characteristic regarding $\Delta P$, ignition timing, and timing of peak $\triangle P$ of the PC2.4 and PC3.6 cases are quite similar.

(2) The negative PLIF imaging indicates the delay between the PC gas exchange and the built-up of the $\Delta P$ due to the gas inertia and resistance of the PC. The PC jet impinges on the piston top and generates intense turbulence in the MC. Distinct PC jet with low speed is witnessed after $15^{\circ} \mathrm{CA}$ ATDC, which could account for the postcombustion phenomenon of our previous metal engine PC experiment with both PC and MC fueling.

(3) The PC jet can be either continuous or intermittent depending on the $\Delta P$ and pressure fluctuation amplitude. Higher $\Delta P$ results in

Page 11 of 13 stronger pressure fluctuation after PC combustion. For the PC1.2 case that shows low $\triangle P$ and pressure fluctuation, the PC jet is continuous. For the PC2.4 and PC3.6 cases with relatively high $\Delta P$ and pressure fluctuation, it presents a three-stage gas exchange. The first stage is the main gas discharge caused by PC combustion. The second-stage gas exchange is due to the $\Delta P$ pressure fluctuation after PC combustion. The third-stage gas exchange rises due to the positive $\Delta P$ caused by the cylinder expansion during power stroke.

(4) The probability distribution analysis of the negative PLIF and $\mathrm{OH}^{*}$ images indicates that the flame jet penetration length is much shorter than that of the PC jet. This means that the flame jet resides in an atmosphere of the unburned gas mixture from the PC when it appears in the MC. The flame jet and PC jet show longer penetration length and become more stable with the enriching of the PC charge from lean condition to stoichiometry. However, the overall PC jet characteristics regarding the penetration length and probability distribution become less sensitive to the PC $\lambda$ when the PC charge is close to stoichiometry.

(5) PC $\lambda$ should be optimized to produce high enough $\Delta P$ and strong $\mathrm{PC}$ jets to generate widely distributed ignition sites and thus faster $\mathrm{MC}$ combustion. Over enrichment (like the PC3.6 case) to the PC charge is not necessary because it does not help with the PC jet intensity and may increase the $\mathrm{UHC}$ and $\mathrm{NO}_{x}$ emissions from the PC.

\section{References}

1. Gussak, L.A., V.P. Karpov, and Y.V. Tikhonov, The Application of Lag-Process in Prechamber Engines. SAE Technical Paper $790692,1979$.

2. Toulson, E., H. Schock, and W. Attard, A Review of PreChamber Initiated Jet Ignition Combustion Systems. SAE Technical Paper 2010-01-2263, 2010.

3. Attard, W.P., N. Fraser, P. Parsons, and E. Toulson, A Turbulent Jet Ignition Pre-Chamber Combustion System for Large Fuel Economy Improvements in a Modern Vehicle Powertrain. SAE Technical Paper 2010-01-1457, 2010.

4. Attard, W.P. and H. Blaxill, A Lean Burn Gasoline Fueled PreChamber Jet Ignition Combustion System Achieving High Efficiency and Low NOx at Part Load, in SAE Technical Paper 2012-01-1146. 2012.

5. Attard, W.P. and H. Blaxill, A Gasoline Fueled Pre-Chamber Jet Ignition Combustion System at Unthrottled Conditions. SAE International Journal of Engines, 2012. 5(2): p. 315-329.

6. Attard, W.P. and P. Parsons, Flame Kernel Development for a Spark Initiated Pre-Chamber Combustion System Capable of High Load, High Efficiency and Near Zero NOx Emissions. SAE Technical Paper 2010-01-2260, 2010.

7. Attard, W.P., H. Blaxill, E.K. Anderson, and P. Litke, Knock Limit Extension with a Gasoline Fueled Pre-Chamber Jet Igniter in a Modern Vehicle Powertrain. SAE International Journal of Engines, 2012. 5(3): p. 1201-1215.

8. Shah, A., P. Tunestal, and B. Johansson, Effect of Pre-Chamber Volume and Nozzle Diameter on Pre-Chamber Ignition in Heavy Duty Natural Gas Engines, in SAE Technical Paper 2015-010867. 2015.

9. Shah, A., P. Tunestal, and B. Johansson, Effect of Relative Mixture Strength on Performance of Divided Chamber 'Avalanche Activated Combustion' Ignition Technique in a Heavy Duty Natural Gas Engine, in SAE Technical Paper 201401-1327. 2014.

10. Biswas, S. and L. Qiao, Ignition of ultra-lean premixed hydrogen/air by an impinging hot jet. Applied Energy, 2018. 228: p. $954-964$. 
11. Biswas, S., S. Tanvir, H. Wang, and L. Qiao, On ignition mechanisms of premixed $\mathrm{CH} 4$ /air and $\mathrm{H} 2$ /air using a hot turbulent jet generated by pre-chamber combustion. Applied Thermal Engineering, 2016. 106: p. 925-937.

12. Murase, E. and K. Hanada, Enhancement of combustion by Injection of radicals. SAE Technical Paper 2000-01-0194, 2000.

13. Gentz, G., B. Thelen, P. Litke, J. Hoke, et al., Combustion Visualization, Performance, and CFD Modeling of a PreChamber Turbulent Jet Ignition System in a Rapid Compression Machine. SAE International Journal of Engines, 2015. 8(2): p. 538-546.

14. Gentz, G.R. and E. Toulson, Experimental Studies of a Liquid Propane Auxiliary Fueled Turbulent Jet Igniter in a Rapid Compression Machine. SAE International Journal of Engines, 2016. 9(2): p. 777-785.

15. Gentz, G., M. Gholamisheeri, and E. Toulson, A study of a turbulent jet ignition system fueled with iso-octane: Pressure trace analysis and combustion visualization. Applied Energy, 2017. 189: p. 385-394.

16. Murase, E. and K. Hanada, Control of the Start of HCCI Combustion by Pulsed Flame Jet. SAE Technical Paper 2002-012867, 2002.

17. Kawabata, Y. and D. Mori, Combustion Diagnostics and Improvement of a Prechamber Lean-Burn Natural Gas Engine. SAE Technical Paper 2004-01-0979, 2004.

18. Toulson, E., A. Huisjen, X. Chen, C. Squibb, et al., Visualization of Propane and Natural Gas Spark Ignition and Turbulent Jet Ignition Combustion. SAE International Journal of Engines, 2012. 5(4): p. 1821-1835.

19. Attard, W.P., E. Toulson, A. Huisjen, X. Chen, et al., Spark Ignition and Pre-Chamber Turbulent Jet Ignition Combustion Visualization, in SAE Technical Paper 2012-01-0823. 2012.

20. Bunce, M., H. Blaxill, W. Kulatilaka, and N. Jiang, The Effects of Turbulent Jet Characteristics on Engine Performance Using a Pre-Chamber Combustor, in SAE Technical Paper 2014-01-1195. 2014.

21. Wellander, R., J. Rosell, M. Richter, M. Alden, et al., Study of the Early Flame Development in a Spark-Ignited Lean Burn FourStroke Large Bore Gas Engine by Fuel Tracer PLIF. SAE International Journal of Engines, 2014. 7(2): p. 928-936.

22. Mastorakos, E., P. Allison, A. Giusti, P. De Oliveira, et al., Fundamental Aspects of Jet Ignition for Natural Gas Engines. SAE International Journal of Engines, 2017. 10(5): p. 2429-2438.

23. Hlaing, P., M. Echeverri Marquez, E. Singh, F. Almatrafi, et al., Effect of Pre-Chamber Enrichment on Lean Burn Pre-Chamber Spark Ignition Combustion Concept with a Narrow-Throat Geometry, in SAE Technical Paper 2020-01-0825. 2020.

24. Hlaing, P., M. Echeverri Marquez, V.S. Bhavani Shankar, E. Cenker, et al., A Study of Lean Burn Pre-Chamber Concept in a Heavy Duty Engine, in SAE Technical Paper 2019-24-0107. 2019.

25. Tang, Q., Y. An, V. Raman, H. Shi, et al., Experimental Study on the Effects of Spray-Wall Interaction on Partially Premixed Combustion and Engine Emissions. Energy \& Fuels, 2019. 33(6): p. 5673-5681.
26. Tang, Q., R. Sampath, P. Sharma, G. Nyrenstedt, et al., Optical Study on the Fuel Spray Characteristics of the Four-ConsecutiveInjections Strategy Used in High-Pressure Isobaric Combustion, in SAE Technical Paper Series. 2020.

27. Miles, P.C., R. Collin, H. Leif, A. Hultqvist, et al., Combined measurements of flow structure, partially oxidized fuel, and soot in a high-speed, direct-injection diesel engine. Proceedings of the Combustion Institute, 2007. 31: p. 2963-2970.

\section{Contact Information}

Qinglong Tang

Postdoctoral Fellow

Clean Combustion Research Center

King Abdullah University of Science and Technology

Building 5, Level 4, Room 4216, WS12

Thuwal 23955-6900, Saudi Arabia

Email: qinglong.tang@kaust.edu.sa

\section{Acknowledgments}

The paper is based upon work supported by Saudi Aramco Research and Development Center FUELCOM3 program under Master Research Agreement Number 6600024505/01. FUELCOM (Fuel Combustion for Advanced Engines) is a collaborative research undertaking between Saudi Aramco and King Abdullah University of Science and Technology (KAUST) intended to address the fundamental aspects of hydrocarbon fuel combustion in engines and develop fuel/engine design tools suitable for advanced combustion modes.

\section{Definitions/Abbreviations}

$\begin{array}{ll}\text { PLIF } & \text { planar laser-induced fluorescence } \\ \text { PCC } & \text { Pre-chamber combustion } \\ \text { PC } & \text { Pre-chamber } \\ \text { MC } & \text { Main chamber } \\ \text { ATDC } & \text { After the top dead center } \\ \lambda & \text { Excess air ratio } \\ \text { NFL } & \text { Natural flame luminosity } \\ \text { PDI } & \text { Probability distribution index } \\ \text { ICCD } & \text { Intensified charge-coupled device } \\ \Delta \boldsymbol{P} & \text { Pressure difference between PC and MC }\end{array}$




\section{Appendix}

Model map for the pre-chamber simulation using 1-D GT-Power.

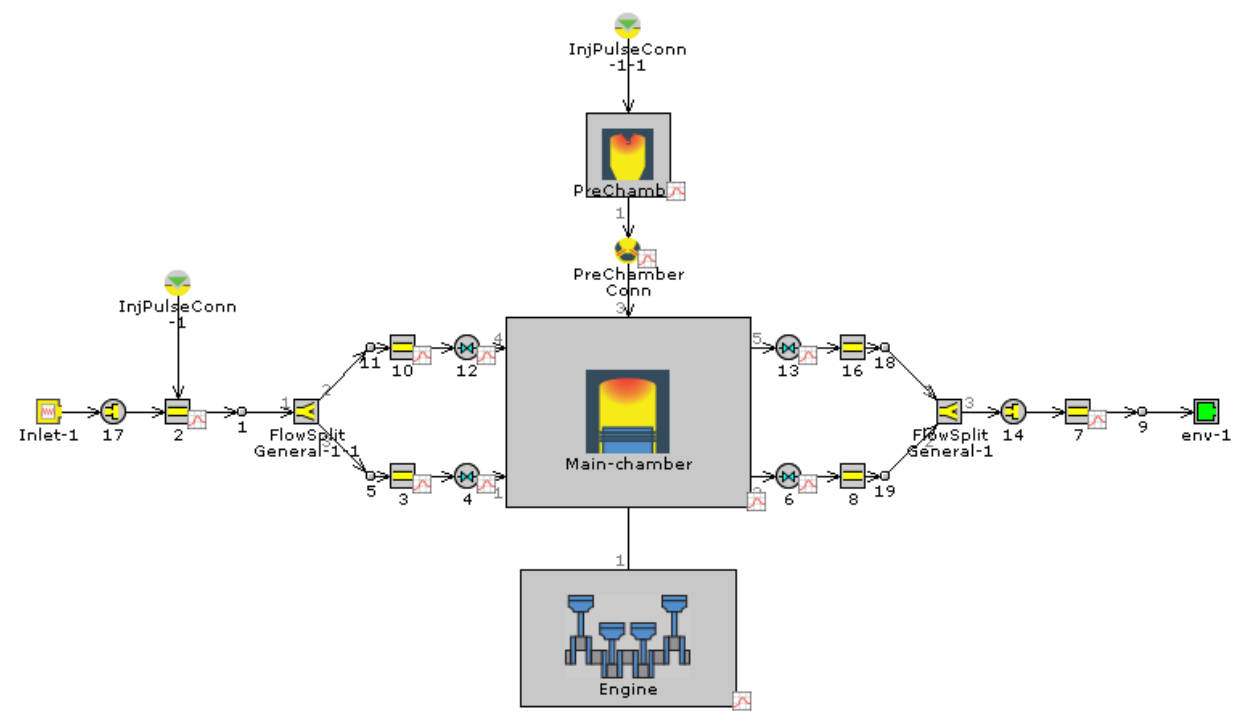

Page 13 of 13 